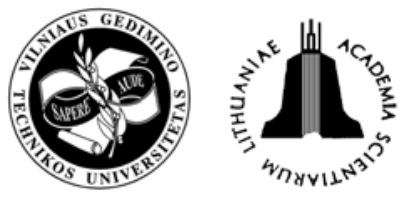

\title{
IMPLEMENTATION OF ADVANCED TECHNOLOGIES AND OTHER MEANS IN DANGEROUS FREIGHT TRANSPORTATION
}

\author{
Nijolè Batarlienè \\ Dept of Transport Management, Vilnius Gediminas Technical University, Plytines g. 27, \\ LT-10105 Vilnius, Lithuania.E-mail:nijbat@ti.vgtu.lt
}

Received 7 April 2007; accepted 10 September 2007

\begin{abstract}
This article examines types of modern technologies application possibilities in dangerous freight transportation. It is noted that the solution to transport technology problems is based on the improvement of technological supply, the rational usage of informational modeling methodology of the whole transportation process. The aspects of mobile solution of public information and transport are named in this paper. The article presents concrete vehicles and freight tracking on their trips analysis, the principles and methods of their operation. Tracking and localization systems are playing a great role in the transportation of dangerous freight. The newly developed remote identification system for transport facilities and freight are presented.
\end{abstract}

Keywords: dangerous freight, safety, transport, requirements for transportation.

\section{Introduction}

The Lithuanian transport system is the most rapidly developing economic sector covering the harmonious entirety of all modes of transport (railways, roads, water and air) and communications. Hundreds of millions of litas are spent for modernization of the transport system each year and this helps in upgrading its technical level to the parameters of the leading European countries. Only modern transport may reliably perform cargo and especially dangerous freight transportation, ensure efficiency and total safety of the economic process.

The transportation of dangerous freight is one of the most complicated spheres of transport and one that requires the most safety measures.

In every day life from the viewpoint of road safety, a vehicle, which carries dangerous freight, is treated the same as every other means of transport. Any particular safety requirements are not asked for. However, during a vehicle crash or a traffic accident, despite the subsequence of every vehicle crash, due to after-effect dangerous freight gets into surrounding environment.

Information technologies provide us with new possibilities in organizing transport work, physical location of transport means place. In Lithuanian scientists' works they are investigated more widely: Internet can be used for electronic data registration of transport means and cargo.

The necessity of mobile transport systems analysis is based on globalization and integration processes; interconnection of various types of transport means and their management in order to obtain more effective, safe and mobile freight motoring and the creation of the in- telligent transport sector. It is necessary to improve the present European transport services and promote new services upbringing, to reveal the shortcomings.

\section{Safety requirements for the transportation of dangerous freight}

Keeping experience in mind, the following safety requirements for dangerous freight transportation could be emphasized:

- Tunnels: limit transportation through tunnels.

- Routes: routes should be selected according to the situation, because there are some roads where transportation, without having a special permission, of dangerous freight is forbidden, if roads are not fitted for the transportation of dangerous freight. General statement indicates that dangerous freight should not be transported close to the habitable areas.

- Bad weather conditions: when visibility on the roads is bad, it is raining, snowing or foggy, the transportation of dangerous freight in major cases should be forbidden. Bad weather conditions are when visibility is less than 200 meters. Some dangerous materials should not be transported, when roads are slippery.

- Ferries: special requirements for the carriage by ferries should be set down. Corresponding ferriage requirements should be applied for every means of the transport, which carries dangerous freight. In some cases the ferriage of dangerous freight should be forbidden [1]. 
Effective and safe dangerous freight transportation is possible only by good provision of information. It is necessary to create an information system of dangerous freight transport based on the database of the regulations of such cargo transportation.

Information system of dangerous freight transportation has to be based on ADR and RID regulations because:

- it is a whole of means, which enable users to manipulate with regulations for dangerous freight transportation;

- it is a methodological base for safer and more perfect transportation of dangerous freight;

- it is a united program, regulating transportation of dangerous freight, predicting juridical and technological basics of dangerous freight transportation.

Every two years computer variants for international transportation of dangerous freight by roads (ADR) and railways (RID) are already prepared, also regulation requirements for dangerous freight transportation by international roads are fitted for the transportation inside the country, requirements for dangerous freight transportation control are prepared for inspectors, according to the EU directives and other work. This work enables to improve the transportation process and to create an information system. It describes the necessity of creating methodological basics for safer and more perfect transportation of dangerous freight.

\section{Modeling of formal data set structure}

Data set structures of dangerous freight transportation are separated considering peculiarities of its dataprocessing technologies, trying to bring stored data closer to its sources and users. It is thought that the main user of information system is a participant in dangerous freight transportation.

While sorting data according to different criteria, particular layout of these criteria enables to direct projection of transport technology to a certain direction. The essence of project depends on this direction. When changing the order of layout we get new projects of transport technology. Data can be added, a part of data can be changed and a part of it may be removed. This can be done without changing the essence of formal system.

Regulations of dangerous freight transportation have to be modeled till the indivisible level so that they would not have any exceptions and references to other regulations. General basis of regulations about transported dangerous freight, their amounts have to be formulated in this way. Transportation of freight and formulation of regulations concerning their conditions in the database have to be separated from conventionality of changing software.

When modeling structure of dangerous freight transportation regulations and projecting information system of dangerous freight transportation, three principles may be distinguished:
- complexity principle;

- decomposition principle;

- hierarchy principle.

The essence of projecting complexity principle: when projecting a dangerous freight transportation system, it is important to analyze as much comprehensively as possible, to evaluate and keep the most essential relations, which are in the operating object as well as in the operating system, also between the outside and inside of information system. Complexity helps to evaluate assumptions, conditions and interaction of different elements more comprehensively and thoroughly, when the computerizing object of dangerous freight transportation is being analyzed. This principle also helps to determine factors, which affect the quality and efficiency of the system, as well as to seek for the most efficient solutions.

Decomposition principle is also important in projecting the structure of an information system. It describes the separation of the whole into parts, seeking to analyze, estimate and project each of them without reference to others. This is the separation of a difficult task into easier ones: for example, sender of data scheme, carrier of data scheme, receiver of data scheme and so on. Database of dangerous freight transportation is separated (structuralized) according to the conveniences of its data-processing technologies, but logical entity and meaningful links between the separated parts have to remain unharmed.

Structuring and analyzing of dangerous freight transportation regulations and database of information system according to the degree of particularity is determined by a hierarchy principle. Structuring is proceeded according to several degrees of particularity. We are going to study more widely the essence and the usage of methodology of this principle.

Several methods can be used for the restructurization and modeling of international regulations for dangerous freight transportation. All of them are related to horizontal or vertical hierarchy method. Its essence: in the highest level of hierarchy, identification number of dangerous material given by the United Nations Organization and name of dangerous material is taken. These records are considered not only as beginning of hierarchy, but also as the main object.

\section{New technologies for location and control of dangerous freight and vehicles}

In solving the problems associated with vehicles and transportation of dangerous freight, one should always know an exact location of transport facility and the freight transported as well as the places of freight loading, unloading and transfer. The information on the past runs on particular routes should also be studied. This could allow us to effectively control all transport facilities as well as to avoid fire explosions of dangerous freight or other accidents. The information of any deviation from the route and other related data should be recorded [2]. 


\subsection{Telematics solutions}

Rapid development of teleinformatics has influence on the development of telematics system. We can distinguish many systems that help drivers and transport clients.

At present telematics solutions are used in road transport. Transport telematics consists of the following aspects:

- transmission of information to and from a vehicle (Telecommunication);

- processing of information (Information Technology);

- information usage for safe transport and effective usage of already existing technologies solutions.

Such changeable light boards as navigation systems, the Internet, mobile network are just a few examples of telematics usage in road transport [3].

Mobile Location is fundamentally characterised by two aspects: mobility and location information.

Mobile Location Services are services that exploit the knowledge about where a mobile terminal capable of wireless data transfer is located. The end user or another person may carry the terminal, or it may be attached to an object. The wireless data connection is typically based on cellular technologies or wireless. Network-based positioning, satellite positioning or indoor positioning technologies can define the location of the terminal. The most suitable technology depends on an application, the environment and the terminal capabilities. As the mobile location services sector is still in its early phases, the terminology varies and they are also called location - based services, location - enhanced services and location - dependant services [4].

Typical professional applications include e.g. fleet and mobile workforce management as well as routing and navigation. Location information is very important in various fields and for various purposes.

\subsection{Software Application}

The catalogue of telematics system has the clientserver structure. All data are stored in a separate place (computer) named the server. Access to its data is possible by a client applications installed into the user's computer. Clients are connected via, for example, a local area network (LAN) or wide area network (WAN). The solution gives many advantages for future users. The central bank of data (server) gives certainty that all users have an access to the same updated data. Any change in the infrastructure telematics system may be input to the catalogue system directly by the service that made the change. It makes possible that the updated data will be available for all users soon after updating. Access to the server's data is restricted depending on the service needed. It is protected against free access to the data for unprivileged persons [5].

The local database stores all necessary information about saved telematics systems, their items, remarks, etc. The digital map server stores a graphic representation of spatial locations where a system's item may be found. The external database module allows users to access to an external temporary database to improve the knowledge about the telematics system. The graphic user interface combines all data coming from different modules into one comprehensible view easy for user to interpret [6]. The map scanner allows the preparation of external maps to use with the system. The last module is responsible for the analysis of loaded data from the server as an answer to user's question. Other function of the last module is the reporting [7]. It is one of the main functions of a catalogue program. Particular parts of the software are presented in Figure.

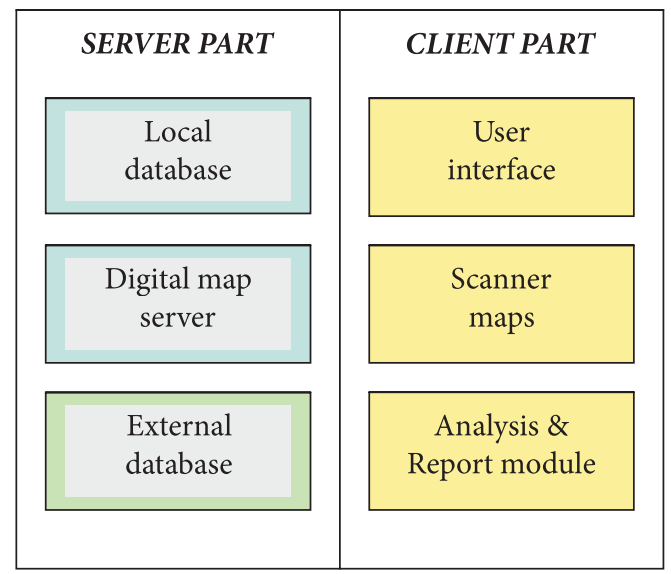

Main parts and modules of the catalogue of telematics system

\subsection{Location system standards}

The emergence of road transport means is supported by telematics solutions, such as:

- traffic monitoring equipment (sensors, detectors, steering equipment, video detectors), television supervision devices (supervising cameras);

- systems of satellite navigation (GPS, GLONASS, EGNOS, GALILEO);

- derivative systems used in navigation;

- systems of radio communication;

- geographical data base (GIS);

- bases of road data;

- electronic cards;

- weather monitoring and measuring systems and other.

The GPS is well known as a global navigation satellite system. The analogous systems are the Russian GLONASS and GALILEO system prepared by the European Commission and European Space Agency. GPS is the foundation of the present navigation systems. Actually, the GPS is the only one fully applicable global satellite position determination system in the world [8].

GALILEO will be Europe's own global navigation satellite system, providing a highly accurate, guaranteed global positioning service under civilian control. It will be inter-operable with GPS and GLONASS, the two other global satellite navigation systems. A user will be able to take a position with the same receiver from any of the satellites in any combination. With the help of the 
systems GALILEO, SBAS, EGNOS, THALES NAVIGATION, etc. objects position may be estimated with the needed precision. It is very important when we want to watch a truck whose position is always changing on the digital map.

For transfer of the coordinated position of the geographical objects global navigation and positioning systems are being used (see the Table):

World satellite navigation and positioning systems

\begin{tabular}{|c|c|c|c|}
\hline No & $\begin{array}{c}\text { Acronym of } \\
\text { system }\end{array}$ & The full name of system & $\begin{array}{c}\text { Regions of } \\
\text { use }\end{array}$ \\
\hline 1 & GALILEO & $\begin{array}{l}\text { European Satellite } \\
\text { Navigation System }\end{array}$ & $\begin{array}{l}\text { In Europe } \\
\text { since } 2008\end{array}$ \\
\hline 2 & SBAS & $\begin{array}{c}\text { Satellite-Based } \\
\text { Augmentation Systems }\end{array}$ & $\begin{array}{c}\text { North } \\
\text { America, } \\
\text { Europe, Asia } \\
\end{array}$ \\
\hline 3 & WAAS & $\begin{array}{c}\text { Wide Area } \\
\text { Augmentation System }\end{array}$ & $\begin{array}{c}\text { North } \\
\text { America } \\
\end{array}$ \\
\hline 4 & EGNOS & $\begin{array}{c}\text { European } \\
\text { Geostationary } \\
\text { Navigation Overlay } \\
\text { Service } \\
\end{array}$ & Europe \\
\hline 5 & MSAS & $\begin{array}{c}\text { MTSAT Satellite Based } \\
\text { Augmentation System }\end{array}$ & Japan \\
\hline 6 & DGPS & $\begin{array}{l}\text { Differential Global } \\
\text { Positioning System }\end{array}$ & In the world \\
\hline 7 & $\begin{array}{c}\text { THALES } \\
\text { NAVIGA- } \\
\text { TION }\end{array}$ & $\begin{array}{l}\text { Thales Navigation \& } \\
\text { Thales Group }\end{array}$ & In the world \\
\hline
\end{tabular}

These systems are the instrumentality for managing land transport in Europe, whether they are transporting by road, rail or inland waterways. They increase both the capacity and the safety of land transport. Not only airlines but also companies, which operate transport services, need to know where their vehicles are at all times [9].

\section{Vehicles and freight mobility positioning systems}

Satellite positioning systems are widely used in the world, which enables to indicate the presence of the object, having the positioning equipment, with the wanted precision. To estimate the geographical position fast and precisely is very important if we want to track the object which changes its position (for example a car, a ship or a plane) on the digital map, especially while transporting dangerous freight by any means of the transport. One of the ways to indicate the geographical position of the object is by using global positioning systems (GPS) [10].

The main factors limitating GIS spread is dependence on maximal computer recourses and that the system is not freely distributed if compared to other programs as it is an expensive product.

The project of Galileo system will be very useful [8]. Informational technologies DHLNET are mostly used for distribution and tracking of air transport freight which is hardly adapted for land transport.

As well as improving safety, world satellite navigation and positioning systems are an invaluable aid in managing transport operations. Managers will be able to know exactly when a consignment has been held up and its exact location. This will also improve customer services as clients can be notified of delays and the reason for them, and when necessary breakdown crews can be sent out immediately.

\section{Freight and vehicle tracking and control systems}

For transfer of the coordinated position of the geographical objects, for tracking of freight and vehicle the control and tracking systems are being used:

- "MOBISAFE" - load vehicle control and supervision system. GSM is used.

- "EUTELTRACS" - integrated satellite system which allows controlling transport and load location. Only satellite link EUTELSAT is used.

- "SEKLYS" - mobile objects control and supervision service. GSM is used.

- "NAVISAT" - transport control system. GSM is used.

- "AUTOGUARD" - vehicle control and security system. GSM is used.

- "SAT TRAC" - satellite vehicle tracking system and other.

Most usually "MOBISAFE" system may be used for all matters where security is needed, for example, transporting valuable freight.

When there is a danger or the crime was committed or the accident happened, "MOBISAFE" receiver is sending alerts immediately containing the exact coordinates to the stand. In order to measure the exact coordinates of the vehicle satellite GPS system is being used. Vehicle coordinates are being sent to the stand. In the control centre computer geographical systems are being used which helps to take care of the tracking of the vehicle and it can be seen on the digital maps of the place or town. Processed information, which is obtained from the satellite, allows indicating the position of vehicle with 10-30 meters bias. That is how it is possible to track the position of the vehicle after the accident and to send help. Or, in case of theft, it is possible to get back vehicle and the load with the help of the police.

"EUTELTRACS" is a complex satellite system that allows controlling transport and loading mobility. It is a mutual alerts connection, navigation, emergency and danger alerts transfer, load and transport parameter observation [14].

"VARICOM EUTELTRACS" satellite centre is a cheap way of transferring data between transport companies dispatcher and earth station organizer. Subscribing to dispatchers's computer connects to the central data system with modems after the numbers and passwords are checked, with no holding on, transfers the alerts to the earth station. Reverse connection runs similarly [11].

Programs in the dispatcher's computer maintain a constant connection with companies' vehicles. "QTRACS - PC" or "GEOTREK" automatically sends data to the earth station by modem as well as takes information that has been submitted. Afterwards "QTRACS - 
PC" or "GEOTREK" processes it and presents to the dispatcher and further it is being used or saved.

"GEOTREK" program is designed for an effective control of vehicle and operative connection between companies' dispatcher and vehicle drivers' support.

"GEOTREK" program has these functions:

- Mutual connection between companies base and vehicle is sending text messages (at concrete and periodical time);

- Provides the possibility to maintain the connection between different vehicles;

- Helps to choose and plan the most optimal routes;

- In Europe, northern Africa, middle Asia situated vehicle can be tracked on digital map with 80-200 meters bias. "GEOTREK" has 250 or 450 maps that are complemented as needed $[12,13]$.

System of control and supervision "SEKLYS" ("Detective") is designed for tracking of mobile objects on the digital maps which can be seen on the computer screen. Mobile objects can be controlled and observed in several ways: through their mobile phone or through OMNITEL “SEKLYS” gates.

With help of receivers the system allows GPS to transfer coordinates by special SMS messages through GSM service "NAVISAT" to Internet gateway. The obtained information is connected with digital maps. Through the Internet subscribers can see the interface on the map.

"AUTOGUARD" system is designed for transport companies, courier, taxi, security and passenger service companies. The efficiency of the system was proved both in big and small parks [14].

Satellite car tracking system "SAT TRAC" is used to track and observe cars. Vehicle can be tracked only in the countries that support mobile networks.

Tracking and location systems play an important role in transportation of dangerous freight because dangerous freight may cause serious danger for the environment and the society.

\section{A remote identification system for freight transport}

Three Lithuanian universities (Kaunas University of Technology, Vilnius University and Vilnius Gediminas Technical University) as well as mobile phone operator "Bite GSM" created the programme "Mobile solutions in information and transport" (VITMOS). Based on this programme researchers developed an effective system of transport registration and monitoring and a mobile portal for public information associated with transport.

During freight transportation a carrier (a company) should get the following data relating to:

- the location of the vehicle and whether the freight are being loaded or unloaded;

- the process of crossing the state border by the vehicle;

- the time of the vehicle's arrival at the terminal;

- observance of work and leisure time by the carrier;

- time of refuelling.
The main parts (units) of the remote identification system of vehicles and freight embrace: TI portal, TVIM portal, content control system (SMS, GPRS), mobile phone, the unit for stating the geographical position of vehicles and freight.

Given such flexibility, services can be provided to a wide range of users, including large logistics companies as well as individual carriers. Both types of portals have access to highly developed mobile phone lines.

To identify freight at a distance from the containers or packages, disposable sensors can be used. They may be made of paper and attached to packages or containers to be monitored. The sensors should be able to read the information automatically.

Dangerous freight requires special precautions. Applying the above described system to transportation of dangerous freight, the main tasks are to ensure monitoring and control. Disposable sensors attached to packages can also be used in this case, particularly, when transporting the most or highly dangerous freight (i. e. autoreactive, radioactive materials, organic peroxides), as well as freight transported:

- by vehicles with the mass exceeding 3.5 tonnes;

- by vehicles carrying dangerous cargoes in fixed or removable tanks of the capacity exceeding $1 \mathrm{~m}^{3}$;

- by a battery of similar transport facilities with the total capacity exceeding $1 \mathrm{~m}^{3}$;

- by containers, removable containers or ddk, with the capacity exceeding $3 \mathrm{~m}^{3}$ per vehicle;

- by vehicles, carrying 1st grade materials or products, irrespective of the largest mass of transport facility.

In transporting dangerous freight, the route of vehicles should be known and a system for moving objects control should be provided. The latter could ensure the safety of the transported dangerous freight.

This system would also be useful for carrying perishables because their transportation should be controlled [3].

\section{Integration into the EU transport systems}

To achieve the integration of Lithuanian transport system into the economic community of European and other countries in the shortest possible time, an efficient transport system informational infrastructure should be created, which is perceived rather as a formation of the operational environment for particular enterprise information systems than the development of a single huge computer-aided information system. In developing these projects, the problem of their future integration into the projects of intelligent transport systems being implemented in Europe now should be considered. Lithuanian information systems in transport should be updated, and their compatibility with similar systems in the neighbouring countries should be ensured.

The program VITMOS is the first development towards this end. Mobile VITMOS solutions, based on the created portals, can be effectively used in the context of European development. Transport problems are paid 
great attention to in the European Union: a strategic directive "e Safety - Cooperative Systems for Road Transport", which has been implemented for several years now, emphasizes the role of transport efficiency, safety, reliability and comfort in solving these problems. At present, the criteria allowing for the creation of cooperative systems for road transport, such as "automobile - automobile" and "automobile - infrastructure" are considered to be of primary importance. Based on them, the following tasks can be defined for future projects:

- to develop the control systems for transport in order to effectively use the available infrastructure;

- to test the architecture of open interactive and variable scale systems; to design and implement open interactive and variable scale systems allowing for the effective use of modern sensors and integrating their software;

- to test and implement open interactive and variable scale systems, using positioning technologies and sensors, and integrate them into intelligent cooperative systems;

- to integrate open interactive and variable scale systems into transport control systems;

- to develop systems for analysing accidents and their causes in particular, integrating them into the systems providing similar data, which are currently used in the EU states;

- to develop and integrate the websites "e Safety Initiative" and "e Safety Forum", especially, as a basis for creating effective technologies aimed to increase traffic safety.

The works performed using the VITMOS program and the experience gained in developing the above projects could provide a foundation for future cooperation with the colleagues abroad.

\section{Conclusions}

1. Implementation of advanced technologies and other means in transportation of dangerous freight, which are used to process information quickly and productively, are fitted for safer transportation of dangerous freight and efficient work: for selection of container, for maximum amount of dangerous freight and determination of allowable transportation norms, for possibility of mixed loading and for preparation of insurance documents and for other decisions.

2. As well as improving safety, world satellite navigation and positioning systems are an invaluable aid in managing transport operations.

3. Tracking and location systems play an important role in transportation of dangerous freight because dangerous freights may cause serious danger for the environment and the society.

4. A system of remote identification of vehicles and freight allows the carrier to determine:

- where the vehicle is and if it is being loaded or unloaded;

- how the vehicle is crossing the state border;
- when the vehicle arrives at the place of destination (terminal).

5. Disposable sensors can be used to identify freight at a distance from the containers or large packages. They may be made of paper and glued to packages or containers to be monitored.

6. The portals TVIMP and TIP can provide their users with various kinds of information, including public, legal, statistical, geographical and other types of information, as well as some confidential data based on vehicle monitoring required for the effective company performance.

7. The works performed using the VITMOS program, as well as the experience gained, could form the basis for speeding up the integration of the transport system of Lithuania into the economic community of European and other countries.

\section{References}

1. BAUBLYS, A.; BATARLIENE, N. et.al. Transport: technologies, economics, environment, health: monograph (Transportas: technologijos, ekonomika, aplinka, sveikata: monografija). Vilnius: Technika, 2003. 876 p. (in Lithuanian).

2. GINEVIČIUS, R.; BIVAINIS, J.; MELNIKAS, B. et al. Contemporary business: perfection priority (Šiuolaikinis verslas: tobulinimo prioritetai): collective monograph. Vilnius: Technika, 2005. 137 p. (in Lithuanian).

3. BATARLIENE, N.; BAUBLYS, A. Mobile solutions in road transport. Transport, 2007, Vol. XXII, No. 1, p. 55-60.

4. LIUTKAUSKAS, V.; MATULIS, D.; PLĖŠTYS, R. Location-based services. Elektronika ir elektrotechnika, 2004, No 3(52), p. 35-39.

5. KAKLAUSKAS, A.; ZAVADSKAS, E. K. Support of internet decisions (Internetinè sprendimų parama). Vilnius: Technika, 2002. 51 p. (in Lithuanian).

6. FLOOD, I.; ISSA, R. A.; CAGLASIN, G. eWork and eBusiness in architecture, engineering and construction. Rinker School of Building Construction, University of Florida, Gainesville, USA, 2002. $241 \mathrm{p}$.

7. SALTENIS, S.; JENSEN, C. S. Indexing of moving objects for location-based services. In Proceedings of ICDE'02, Toronto, 2002, p. 463-472.

8. GALILEO - European satellite navigation system. Directorate - General Energy and Transport. Available from Internet: <http://europa. eu.int/comm/dgs/energy_transport/ galileo/index_en.htm>.

9. Website of eSafety research docs. Available from Internet: $<$ www.cordis.lu/ist/so/esafety/publications.htm $>$.

10. Website of Incheon Transportation information service site. Available from Internet: <http://www.intis.net $>$.

11. Website of Company "Varicom". Available from Internet: $<$ http://www.varicom.lt/>.

12. Website of Company "Admita". Available from Internet: $<$ http://www.admita.lt/>.

13. Website of a cave mapping software package designed to edit, process, analyze and view cave survey data using an IBM PC compatible computer. Available from Internet: $<\mathrm{http}: / /$ fountainware.com/compass $>$.

14. Website of Company "Autoguard" of Poland. Available from Internet: <http://www.autoguard/pl >. 